\title{
Prevalence and main outcomes of placenta accreta spectrum: a systematic review and metaanalysis
}

Eric Jauniaux ${ }^{1}, \mathrm{MD}, \mathrm{PhD}$, Catey Bunce ${ }^{2}$, DSc, Lene Grønbeck ${ }^{3}, \mathrm{MD}$, and Jens Langhoff-Roos ${ }^{3}, \mathrm{MD}, \mathrm{PhD}$

1. EGA Institute for Women's Health, Faculty of Population Health Sciences, University College London (UCL), London, UK.

2. Department of Primary Care \& Public Health Sciences, Faculty of Life Sciences and Medicine, Kings College London, London UK.

3. Department of Obstetrics, Rigshospitalet, University of Copenhagen, Denmark.

Declaration of interests: The authors report no conflict of interest

No funding was obtained for this study. "CB's post is part funded/supported by the National Institute for Health Research (NIHR) Biomedical Research Centre based at Guy's and St Thomas' NHS Foundation Trust and King's College London. The views expressed are those of the author(s) and not necessarily those of the NHS, the NIHR or the Department of Health." http://orcid.org/0000-0002-0310-2518

Corresponding author: Professor Eric Jauniaux, EGA Institute for Women's Health, University College London, 86-96 Chenies Mews, London WC1E 6HX, UK.

Telephone numbers: $+44 / 207 / 3908113$

Fax: $+44 / 207 / 3908115$

E-mail: e.jauniaux@ucl.ac.uk 
Condensation: High heterogeneity in prevalence data between population and cohort studies is due to wide variations in diagnostic criteria in diagnosing accreta placentation at birth.

Short title: Prevalence and outcome of placenta accreta spectrum.

\section{AJOG at a Glance}

- A. Why was this study conducted? From a rare pathologic condition of placentation, placenta accreta spectrum is now a new risk factor for major obstetric complications but its epidemiology has not yet been comprehensively studied.

- B. What are the key findings? Large amounts of heterogeneity were found between population studies for prevalence, incidence of peripartum hysterectomy and haemorrhages requiring transfusions due to inconsistency between the different types of population studies with regards to the criteria used to diagnose and confirm the condition at birth.

- C. What does this study add to what is already known? Accurate estimation of the prevalence and outcome of placenta accreta spectrum is currently problematic because of the varying use of clinical criteria to define it at birth and the lack of detailed pathologic examination. 


\section{Abstract}

Objective: The objective of this study was to evaluate the prevalence of placenta accreta spectrum in general population studies and the main maternal outcomes at delivery.

Study design: Data sources: We searched PubMed, Google Scholar, clinicalTrials.gov and MEDLINE between 1982 and 2018. Study eligibility criteria: Articles providing data on the number of cases of placenta accreta spectrum per pregnancies, births or deliveries in a defined population. Study appraisal and synthesis methods: Study characteristics were evaluated by two independent reviewers using a predesigned protocol. Primary outcomes were the prevalence of placenta accreta spectrum and clinical diagnostic at birth and pathologic criteria used to confirm the diagnosis. Secondary outcomes included cases requiring transfusion, incidence of peripartum hysterectomy and maternal mortality rates. Heterogeneity between studies was analysed with the Cochran's Q-test and the $\mathrm{I}^{2}$ statistics.

Results: Of the 98 full-text studies identified, 29 articles met the defined criteria including 22 retrospective and 7 prospective studies comprising 7,001 cases of placenta accreta spectrum out 5,719,992 births. Prevalence rates ranged between 0.01 and $0.1 \%$ with an overall pooled prevalence of $0.17 \%(95 \% \mathrm{Cl} 0.14-0.19)$. Only 10 studies provided with detailed histopathologic data. The pool prevalence for the adherent versus the invasive grades was $0.5(95 \% \mathrm{Cl} 0.3-0.36)$ and $0.3(95 \% \mathrm{Cl} 0.2-0.4)$ per 1000 births, respectively. The pooled incidence for peripartum hysterectomy was $52.2 \%$ 
$\left(95 \% \mathrm{Cl} 38.3-66.4 ; \mathrm{I}^{2}=99.8 \%\right)$ and $46.9 \%\left(95 \% \mathrm{Cl} 34-59.9, \mathrm{I}^{2}=98.8 \%\right)$ for haemorrhage requiring transfusion. The pooled estimate of maternal death was $0.05 \%$ $\left(95 \% \mathrm{Cl} 0.06-0.69, I^{2}=73 \%\right)$. We found large amounts of heterogeneity between studies for all parameters and further quantifying was limited because of methodological inconsistencies between studies with regards to clinical criteria used for the diagnosis of the condition at birth and the histopathologic confirmation of the diagnosis and differential diagnosis between adherent and invasive accreta placentation.

Conclusions: This meta-analysis indicates wide variation between studies for the prevalence rate of placenta accreta spectrum and for the different grades of accreta placentation, highlighting the need for consistency in definitions used to describe placenta accreta spectrum at birth and in reporting on this increasing common obstetric complication.

Key Words: Placenta accreta spectrum; invasive placentation; prevalence; epidemiology; cesarean section. 


\section{Introduction}

Placenta accreta spectrum is a pathologic condition of placentation where the villous tissue adheres or invades the uterine wall. ${ }^{1,2}$ The abnormally adherent grade of placenta spectrum accreta, also described by early pathologists as "placenta creta" or "placenta vera", refers to villous tissue that is attached directly to the underlying myometrium without interposing decidua. The invasive grades include placenta increta when the villi invade the myometrium down to the uterine serosa and placenta percreta when the villi cross the entire uterine wall and may reach the surrounding pelvic organs and vasculature.$^{1,2}$ Both the adherent and invasive grades of placenta accreta spectrum lead to failure of parts or the whole placenta to separate spontaneously from the uterine wall at delivery. ${ }^{1,2}$

The main anatomical impact of placenta accreta spectrum is at the level of the deep uterine vasculature ${ }^{2}$ and when unsuspected at the time of delivery, attempts to manually remove accreta placental tissue typically provoke rapid massive obstetric haemorrhage. ${ }^{3}$ The risk is particularly high in invasive cases due to the disruption of the main branches of uterine arteries and the possible invasion of the bladder wall and surrounding pelvic vessels. ${ }^{4,5}$ Women with placenta accreta spectrum are also more likely to deliver early $y^{6,7}$ and most cases of placenta increta and percreta require complex surgical management often involving different surgical specialists, interventional radiologists, intensivist anesthesiologists, hematologists and neonatologists. ${ }^{5,8}$ Prenatal diagnosis has been shown to decrease maternal morbidity and has thus become crucial in improving the management of placenta accreta spectrum. ${ }^{9-11}$ Recent retrospective cohort studies from the US have also shown that women managed by a multidisciplinary team in centre of excellence were less likely to require emergency surgery, large-volume 
blood transfusions and reoperation within a week of delivery compared with women managed by standard obstetric care without a specific protocol. ${ }^{12-16}$

Access to specialist centres, to blood products for transfusion and neonatal and maternal intensive care is variable in many high-income countries and often limited or non-existent in most middle- and low-income countries. The 2017 report from the UK and Ireland Confidential Enquiries into Maternal Deaths has indicated that although there was no overall significant change in maternal death rates in the UK, between 2010-12 and 2013-15, there has been an increase in the mortality rate of women presenting with abnormal placentation. ${ }^{17}$

Cesarean sections are an essential component of a functioning and comprehensive maternity system in all countries but health interventions, in particular in low-income countries, have been mainly focused on access to safe obstetric surgical and anaesthesia procedures. However, population studies ${ }^{18,19}$ and a recent systematic review and metaanalysis ${ }^{20}$ have shown a strong association between cesarean delivery rates, number of prior cesarean sections and the incidence of accreta placentation in subsequent pregnancies. There has been a worldwide increase in cesarean section rates, with rates rising from less than $7 \%$ in 1990 s to well over the $10-15 \%$ World Health Organization (WHO) upper limit at the population level, in the last two decades. ${ }^{21,22}$ In many middle- and high-income countries caesarean section rates have reached $25-30 \%$ of all deliveries without any improvement in maternal and neonatal mortality. ${ }^{22}$ In some middle-income countries such as Turkey, Mexico, Brazil and Egypt more than half of births are via cesarean, mostly elective. As a consequence, in countries with high-birth rate, like Egypt ${ }^{23}$, the prevalence of placenta accreta spectrum 
and its impact on maternal morbidity and mortality will rapidly outweigh the benefit of improving access to quality obstetric care.

Considering the rapid increase in caesarean delivery rates worldwide in the last decade, we undertook a systematic review and meta-analysis on the prevalence of placenta accreta spectrum in general obstetric population studies. The main objective was to assess the sources of heterogeneity across studies in reporting on the clinical diagnostic criteria used to identify and confirm the different grades of placenta accreta spectrum at birth and evaluate their possible impact on the incidence on main maternal outcome data.

\section{Materials and Methods}

\section{Eligibility criteria, information sources and search strategy}

We undertook a PubMed, Google Scholar, clinicalTrials.gov and MEDLINE search for studies published in any language between the first prenatal ultrasound description of placenta accreta in July 1982 by Tabsh et al ${ }^{24}$ and the 1 st of April 2018. The search protocol was designed a priori and registered on PROSPERO (CRD42017068589) (www.crd.york.ac.uk/PROSPERO) in line with current recommendations and reported as per PRISMA 2009 guidelines (www. prisma-statement.org). We used MeSH headings, text words, and word variants for "placenta accreta", "placenta increta", "placenta percreta", "abnormally invasive placenta", "morbidly adherent placenta“. We combined these with terms related to "prevalence ", "maternal morbidity" "maternal mortality", "obstetric haemorrhage", "peripartum hysterectomy" and "cesarean 
hysterectomy“. We screened titles and abstracts of all citations for potentially relevant papers. Full-texts were independently assessed by two authors (EJ and JLS) for content, data extraction and analysis. Additional relevant studies were identified from reference lists of reviews and editorials.

\section{Study selection}

We defined the prevalence of placenta accreta spectrum as the number of cases found in general populations according to the total numbers of pregnancies, births or deliveries (in the main text of each study). We excluded studies published before July 1982, cohort studies of specific conditions increasing the risk of placenta accreta spectrum, cohort studies with less than 10 cases and case reports.

\section{Data extraction}

Clinical study characteristics were subsequently extracted independently by 2 reviewers (EJ and LG) using a predesigned data extraction form including for all studies: year of publication, country of origin, years of study, study type. The primary outcomes were the number of cases of placenta accreta spectrum in the corresponding obstetric population, the different clinical criteria used for the diagnosis of placenta accreta spectrum at birth and pathologic confirmation of the clinical diagnosis including the depth (grades) of villous invasiveness. Secondary outcomes included obstetric the incidence of peripartum hysterectomies, the number of cases of obstetric haemorrhage requiring transfusion and direct maternal mortality.

\section{Assessment of risks of bias}


The Quadas-2 tool for the quality assessment of diagnostic accuracy studies was used to score the methodological quality of the included articles. ${ }^{25}$ The quality items assessed were study design and the conduct and analysis of all included studies. Each item was scored 'high' or 'low', or 'unclear' if there was insufficient information to make an accurate judgment on the risk for bias. No study was excluded based on the risk of bias assessment. Two independent reviewers (EJ and LG) undertook the quality assessment. Discrepancies were resolved with evaluation from the third reviewer (JLS). We assessed the following criteria: main study characteristics, description of clinical criteria used to diagnose the placenta accreta spectrum at birth, detailed histopathologic confirmation and description of the main management interventions.

\section{Data synthesis}

Meta-analyses were conducted to evaluate the variation in study outcomes between studies using STATA software (version 15; StataCorp, College Station, TX). A random effects model was used to combine the studies while incorporating variations among studies unless there were three or less studies contributing to the meta-analysis in which case a fixed effect model was used. Statistical heterogeneity was assessed with the Cochran's Q-test and the $I^{2}$ statistic (the proportion of variation in study estimates because of heterogeneity rather than sampling error). The metaprop routine was used which provides procedures for pooling proportions in a meta-analysis and uses confidence intervals based on score or exact binomial procedures. Meta-regression was used to assess whether variability amongst study estimates was due to the study being prospective or retrospective. Forest plots are presented to graphically summarize the 
study results and the pooled results. A test for heterogeneity between sub-groups (i.e. study type) was conducted. The Pearson chi-square test was used to compare the distribution of the different grades of placenta accreta spectrum in the different types of studies. A p value of $<0.05$ was considered significant.

\section{Results}

\section{Study selection}

From 2170 citations identified we included 29 population studies from 13 different countries for the quantitative analysis. (Figure 1).

\section{Study characteristics}

There were 22 retrospective studies ${ }^{14,26-46}$ and seven prospective. ${ }^{19,47-52}$ Twenty-eight (28/29) were published after the year 2000 (Table 1). There were 18 studies from a single institution ${ }^{14,26-31,33,36-40,42,44}$, three involving two affiliated institutions ${ }^{32,34,51}$, two studies from the National Institute of Child Health and Human Development MaternalFetal Medicine Units Network ${ }^{48,50}$, two regional studies ${ }^{43,46}$, three national studies ${ }^{41,45,49}$ and two international studies involving four ${ }^{19}$ and two $0^{52}$ countries, respectively.

The clinical criteria described by the authors for the clinical diagnosis of placenta accreta spectrum at delivery felt into three categories (Table 2): basic description $32,34,35,38-40,44,47,48,50,51$; extended description ${ }^{27,30,33 ;}$; and World Health Organization (WHO) international classification. ${ }^{19,36,43,46}$ More than a third of the studies $(11 / 29)^{14,26,29,31,37,41,42,45,49,52}$ did not describe the clinical criteria used for the diagnosis of placenta accreta spectrum at birth. Lateral extension of the accreta areas and detailed 
description of the uterine vasculature anatomical changes associated with invasive placentation were not reported by any of the 29 studies.

Six studies ${ }^{14,26,30-32,42}$ used the histologic description proposed by Irving and Hertig ${ }^{53}$ i.e. absence of decidua between the placental villi and uterine myometrium, to confirm the clinical diagnosis (Table 2). Three studies ${ }^{34,35,38}$ reported on the invasion of the myometrium by placental villous tissue and four studies $20,45,46,50$ reported having confirmed the clinical diagnosis by pathologic examination at birth but with no description or reference to the criteria used. Detailed histopathologic data on the depth of villous invasiveness were only reported by ten studies ${ }^{14,29,30,31,36-38,42,49,52}$ and included $473 / 757(62.5 \%)$ cases of placenta creta, $117 / 757(15.4 \%)$ placenta increta and 167/757 (22.1\%) placenta percreta (Table 3).

Twenty-seven out of 29 studies (90\%) reported on surgical management including 1656 cases out of 6007 patients managed by peri-partum hysterectomy (Table 4). Data on the number of blood transfusion was provided by half of the studies (16/29) including 1146 cases out of 4562 patients requiring a transfusion. Information on maternal death were reported in 23 studies with a total of 20 maternal deaths out of 4382 patients. One study reported 13 cases of maternal death ${ }^{39}$, two studies ${ }^{40,52}$ reported two maternal deaths and three studies ${ }^{26,27,33}$ reported one maternal death. The other studies reported no maternal death. Seven studies $28,30,43-45,48$ reported no data on maternal mortality.

\section{Risks of bias of included studies}


The quality of the studies is shown in Figure 2. Fourteen of the included studies had a risk of bias for patient selection, 16 for the index test, 16 for the reference standard and 18 for flow and timing.

\section{Synthesis of results}

A total of 7001 cases of placenta accreta spectrum out of $5,719,992$ births or pregnancies were included in the analysis. The metaanalysis showed a pooled prevalence of $0.17 \%(95 \% \mathrm{Cl} 0.14-0.19)$ for placenta accreta spectrum in 29 studies included in the review. There was considerable heterogeneity in prevalence data between studies with an $\mathrm{I}^{2}$ value of $99.4 \%$ (Figure 3). We explored whether this heterogeneity was due to study design but even looking at the retrospective and prospective studies separately, there was considerable heterogeneity with $\mathrm{I}^{2}$ values ranging between $98.5 \%$ and $99.5 \%$. The prevalence of placenta accreta spectrum in the different types of population studies is presented in Table 5. There was significant $(p<0.001)$ in-between studies heterogeneity $\left(I^{2}=99.4 \%\right)$.

The overall pooled estimate for peripartum hysterectomy was $52.2 \%(95 \% \mathrm{Cl}$ $\left.38.3-66.4 ; I^{2}=99.8 \%\right)$ and $46.9 \%\left(95 \% \mathrm{Cl} 34\right.$ to $\left.59.9 ; I^{2}=98.8 \%\right)$ for haemorrhage requiring transfusion. The overall pooled estimate of maternal death was $0.05 \%$ (95 \% Cl $\left.0.06-0.69 ;\left.\right|^{2}=73 \%\right)$.

The pooled prevalence for the different grades of placenta accreta spectrum was $0.5\left(95 \% \mathrm{Cl} 0.3-0.36 ; \mathrm{I}^{2}=94.8 \%\right)$ per 1000 births for placenta creta (adherent) grade compared to $0.3\left(95 \% \mathrm{Cl} 0.2-0.4 ; \mathrm{I}^{2}=92.7 \%\right)$ per 1000 births for the abnormally invasive placenta category combining placenta increta and percreta (Table 6). 


\section{Comment}

\section{Principal findings of the study}

Our findings have quantified the variability between populations studies in the prevalence of placenta accreta spectrum at birth. There was strong evidence of inconsistency between the different types of population studies with regards to the criteria used to diagnose and/or confirm the condition at delivery. The metaanalysis found large amounts of heterogeneity for the incidence peripartum hysterectomy and for haemorrhage requiring transfusion and moderate amounts for maternal death rates. These findings highlight the effect of the absence of standardisation in reporting on placenta accreta spectrum in many cohort studies. This affects all study types independently of their study design and impairs the evaluation of the corresponding maternal outcomes and the efficacy of different management strategies and techniques.

\section{Results of the Study in the Context of Existing Literature}

The reported prevalence of placenta accreta spectrum seems to have always been highly variable. In their literature review, Lukes et al ${ }^{54}$ found that before 1966, the combined prevalence of adherent and invasive placenta accreta ranged between in 1 in 948 and 1 in 40,000 deliveries. An expert review of the literature between 1977 and 2012 on maternal and neonatal outcomes in placenta accreta, found that the pooled prevalence during that period was 1 in 588 deliveries..$^{55}$ In the present review, the prevalence of placenta accreta spectrum in population studies published between 1982 and 2018 ranged between around 1 in $100^{27,45}$ and 1 in $10,000{ }^{26,40}$ These data are directly 
influenced by the characteristics of the studies included in the review (Table 1). In particular, we found a two-fold increase in the prevalence of placenta accreta spectrum in retrospective compared to prospective studies and a three- to five-fold increase in institution, network and regional studies compared to national and international studies (Table 5). Institution and network studies usually involve centers with expertise in the diagnosis and management of placenta accreta spectrum and this could explain the higher prevalence of the condition in the corresponding populations.

\section{Clinical Implications}

Maternal outcomes in placenta accreta spectrum disorders depend on the identification of the condition before or during delivery and in particular on the differential diagnosis between its adherent and invasive forms. A third of the studies included in this review did not provide a description of the clinical criteria used for the diagnosis at birth and none of them reported on the anatomical changes of the uterine vasculature ${ }^{2}$ that should alert the surgeon to the presence of invasive accreta placentation. If the surgeon is unaware of the diagnostic signs of the different grades of placenta accreta spectrum, attempt at delivering the placenta at the time of repeat cesarean section will lead to rapid bleeding from the placentation site. In this case, the patient outcome will depend on the surgical skills of the attending obstetrician at performing a complex hysterectomy procedure but also on immediate access to blood for massive transfusion and postoperative adult intensive care.

Many of studies included in the present review have used the clinical and histopathologic criteria described in 1937 by Irving and Hertig for abnormally adherent 
placenta accreta. ${ }^{53}$ The clinical symptoms of placenta accreta spectrum disorders, in particular in cases of a partially adherent placenta (creta), can be very similar to those of placental retention, i.e. difficult manual, piecemeal removal of the placenta, absence of spontaneous placental separation 20-30 min after birth despite active management, retained placental fragment requiring curettage after vaginal birth and heavy bleeding from the placentation site after removal of the placenta during cesarean delivery. These criteria have been used by several authors in this review. ${ }^{27,30,33,20}$ However, a retained placenta, which is merely entrapped in the uterus after childbirth owing to constriction of the cervix, should not be included in the category of placenta accreta spectrum nor should cases where a retained placenta is easily removed within $30 \mathrm{~min}$ to $24 \mathrm{~h}$ after birth. Overall, the criteria used by most authors of cohort and population studies to describe individual cases of placenta accreta spectrum have been highly variable and the WHO ICD-10 classification provides no clinical description of the condition and in particular no clue on the differential diagnosis between adherent and invasive accreta placentation (Table 2). This can explain the wide heterogeneity in prevalence in the studies analyzed in the present review and emphasizes the need to involve perinatal pathologists in multidisciplinary team.

\section{Research implications}

Controversies still exist among experts regarding optimal timing of delivery, use of adjunctive measures, and conservative (uterine-sparing) methods. ${ }^{3}$ The principal management approach to controlling excessive bleeding due to accreta placentation 
during delivery has been and remains for the majority of specialists around the world to perform a primary cesarean hysterectomy leaving the placenta in situ. ${ }^{3,56-59}$

Recent cohort studies have shown that prenatal diagnosis of placenta accreta spectrum allows planned delivery by a multidisciplinary team and thus reduces maternal peripartum haemorrhage and morbidity. ${ }^{60,61}$ However, despite more than 35 years of experience in ultrasound imaging diagnosis of placenta accreta spectrum ${ }^{24}$, there are currently no national screening protocols and population studies in high-income countries have shown that placenta accreta spectrum remains undiagnosed before delivery in-between half ${ }^{49,50}$ and two-thirds of cases. ${ }^{19}$

The rates of blood transfusion and peripartum hysterectomy provide indirect estimates of management strategies of placenta accreta spectrum. The deeper the villous tissue invades and the large the accreta area, the more complex the management and the higher the risk of poor outcome. Maternal mortality of placenta accreta spectrum has been previously reported to be as high as $7 \%$ of cases. ${ }^{62}$ The authors of a decisionanalytic model built using data on national birthing order trends after cesarean delivery in the U.S. between 1995 and 2005 have estimated that if primary and secondary cesarean rates continue to rise, by 2020 the rate will be $56.2 \%$, and as a consequence there will be an additional 6236 placenta praevias, 4504 placenta accreta, and 130 maternal deaths annually. ${ }^{63}$ In the present review, one study from India ${ }^{39}$ accounted for 13 of the 20 cases of maternal death and may due to local conditions such as access to prenatal diagnosis, specialist surgeons, blood transfusion and intensive care facilities. The disproportionately high prevalence of placenta accreta spectrum and low rates of peripartum hysterectomy 
in several studies (Table 4) suggest a high rate of misclassification with regards to placental retention in the corresponding population.

These data highlight the need to standardize the definition and classification of placenta accreta spectrum to identify the real healthcare burden of this condition. Whilst the concept of core outcome measures within clinical trials is now well recognised and championed, greater efforts to disseminate this approach in epidemiological research is needed to facilitate global estimation and recognition of new obstetric complications emerging on a global scale.

\section{Strengths and limitations}

This large and comprehensive systematic review and metaanalysis provides the first critical evaluation of the global epidemiology of placenta accreta spectrum. Before this review, data on the prevalence of placenta accreta spectrum were mainly based on individual observational studies and expert reviews.

The main limitations of this review are the publications bias of mainly retrospective and single institutions studies and considerable variation between studies which may impact on the interpretation of the analysis of outcome data. It is also possible that some of the data of single institution may have been included in specialist network analysis and reports but the numbers are probably small. The lack of data on the depth of accreta placentation in most studies of the present review limits also the evaluation of differences in outcome between the adherent and invasive accreta placentation. In addition, outcomes such as amount of blood loss or blood transfused 
are not reported or reported as mean values by most authors, limiting the overall outcome analysis.

\section{Conclusions}

The current knowledge of the epidemiology of placenta accreta spectrum limits the capacity building of healthcare providers on improvements in training, implementation of guidelines and changes in clinical practice. Our data highlight the need to standardize the definition, clinical description and classification of placenta accreta spectrum at the international level to better identify the healthcare burden of this condition and facilitate its estimation and recognition on a global scale. This information is necessary for prospective studies with participatory methodologies involving local service providers to accurately evaluate the consequences of increasing cesarean sections rates within particular population context. 


\section{REFERENCES}

1. Jauniaux E, Jurkovic D. Placenta accreta: pathogenesis of a 20th century iatrogenic uterine disease. Placenta. 2012;33:244-51.

2. Jauniaux E, Collins SL, Burton GJ. Placenta accreta spectrum: Pathophysiology and evidence-based anatomy for prenatal ultrasound imaging. Am J Obstet Gynecol. 2018;218:75-87.

3. Silver RM, Branch DW. Placenta Accreta Spectrum. N Engl J Med. 2018;378:1529-36.

4. Marcellin L, Delorme $P$, Bonnet MP, et al. Placenta percreta is associated with more frequent severe maternal morbidity than placenta accreta. Am J Obstet Gynecol. 2018 doi: 10.1016/j.ajog.2018.04.049.

5. Hubinont $C$, Mhallem M, Baldin P, Debieve F, Bernard P, Jauniaux E. A clinicopathologic study of placenta percreta. Int J Gynaecol Obstet. 2018;140:365-9.

6. Seet EL, Kay HH, Wu S, Terplan M. Placenta accreta: depth of invasion and neonatal outcomes. J Matern Fetal Neonatal Med. 2012;25:2042-5.

7. Chantraine F, Nisolle M, Petit P, Schaaps JP, Foidart JM. Individual decisions in placenta increta and percreta: a case series. J Perinat Med. 2012;40:265-70.

8. Clausen C, Lönn L, Langhoff-Roos J. Management of placenta percreta: a review of published cases. Acta Obstet Gynecol Scand. 2014;93:138-43.

9. Chantraine F, Braun T, Gonser M, Henrich W, Tutschek B. Prenatal diagnosis of abnormally invasive placenta reduces maternal peripartum hemorrhage and morbidity. Acta Obstet Gynecol Scand. 2013;92:439-44. 
10. Weiniger CF, Einav S, Deutsch L, Ginosar Y, Ezra Y, Eid L. Outcomes of prospectively-collected consecutive cases of antenatal-suspected placenta accreta. Int J Obstet Anesth. 2013;22:273-9.

11. Hall T, Wax JR, Lucas FL, Cartin A, Jones M, Pinette MG. Prenatal sonographic diagnosis of placenta accreta: Impact on maternal and neonatal outcomes. J Clin Ultrasound. 2014;42:449-55.

12. Eller AG, Bennett MA, Sharshiner M, Masheter C, Soisson AP, Dodson M, et al. Maternal morbidity in cases of placenta accreta managed by a multidisciplinary care team compared with standard obstetric care. Obstet Gynecol. 2011;117:331-7.

13. Silver RM, Fox KA, Barton JR, Abuhamad AZ, Simhan H, Huls CK, Belfort MA, Wright JD. Center of excellence for placenta accreta. Am J Obstet Gynecol. $2015 ; 212: 561-8$

14. Al-Khan A, Gupta V, Illsley NP, Mannion C, Koenig C, Bogomol A, et al. Maternal and fetal outcomes in placenta accreta after institution of team-managed care. Reprod Sci. 2014;21:761-71.

15. Shamshirsaz AA, Fox KA, Salmanian B, Diaz-Arrastia CR, Lee W, Baker BW, et al. Maternal morbidity in patients with morbidly adherent placenta treated with and without a standardized multidisciplinary approach. Am J Obstet Gynecol. 2015;212:218.e1-9.

16. Shamshirsaz AA, Fox KA, Erfani H, Clark SL, Salmanian B, Baker BW et al.,Multidisciplinary team learning in the management of the morbidly 
adherent placenta: outcome improvements over time. Am J Obstet Gynecol. 2017;216:612.e1-612.e5.

17. Knight M, Nair M, Tuffnell D, Shakespeare J, Kenyon S, Kurinczuk JJ (Eds.) on behalf of MBRRACE-UK. Saving Lives, Improving Mothers' Care - Lessons learned to inform maternity care from the UK and Ireland Confidential Enquiries into Maternal Deaths and Morbidity 2013-15. Oxford: National Perinatal Epidemiology Unit, University of Oxford; 2017 [www.npeu.ox.ac. uk/mbrrace-uk].

18. Silver RM, Landon MB, Rouse DJ, Leveno KJ, Thom EA EA, Moawad AH et al. National Institute of Child Health and Human Development Maternal-Fetal Medicine Units Network. Maternal morbidity associated with multiple repeat cesarean deliveries. Obstet Gynecol 2006;107:1226-32.

19. Thurn L, Lindqvist PG, Jakobsson M, Colmorn LB, Klungsoyr K, Bjarnadóttir RI, et al. Abnormally invasive placenta-prevalence, risk factors and antenatal suspicion: results from a large population-based pregnancy cohort study in the Nordic countries. BJOG. 2016;123:1348-55.

20. Keag OE, Norman JE, Stock SJ. Long-term risks and benefits associated with cesarean delivery for mother, baby, and subsequent pregnancies: Systematic review and meta-analysis. PLoS Med. 2018;15:e1002494.

21. Betrán AP, Ye J, Moller AB, Zhang J, Gülmezoglu AM, Torloni MR. The Increasing Trend in Caesarean Section Rates: Global, Regional and National Estimates: 1990-2014. PLoS One. 2016;11:e0148343.

22. Ye J, Zhang J, Mikolajczyk R, Torloni MR, Gülmezoglu AM, Betran AP. Association between rates of caesarean section and maternal and neonatal 
mortality in the 21st century: a worldwide population-based ecological study with longitudinal data. BJOG. 2016;123:745-53.

23. Shaaban MM, Sayed Ahmed WA, Khadr Z, El-Sayed HF. Rising cesarean section rates, a patient's perspective: experience from a high birth rate country. Clin Exp Obstet Gynecol. 2014;41:436-9.

24. Tabsh KM, Brinkman CR 3rd, King W. Ultrasound diagnosis of placenta increta. J Clin Ultrasound. 1982;10:288-90.

25. Whiting PF, Rutjes AW, Westwood ME, Mallett S, Deeks JJ, Reitsma JB et al; QUADAS-2 Group. QUADAS-2: a revised tool for the quality assessment of diagnostic accuracy studies. Ann Intern Med. 2011;155:529-36.

26. Makhseed M, Moussa MA. Placenta accreta in Kuwait: does a discrepancy exist between fundal and praevia accreta? Eur J Obstet Gynecol Reprod Biol. 1999;86:159-63.

27. Gielchinsky Y, Rojansky N, Fasouliotis SJ, Ezra Y. Placenta accreta--summary of 10 years: a survey of 310 cases. Placenta. 2002;23:210-4

28. Sheiner E, Levy A, Katz M, Mazor M. Identifying risk factors for peripartum cesarean hysterectomy. A population-based study. J Reprod Med. 2003;48:6226.

29. Armstrong CA, Harding S, Matthews T, Dickinson JE. Is placenta accreta catching up with us? Aust N Z J Obstet Gynaecol. 2004;44:210-3.

30. Wu S, Kocherginsky M, Hibbard JU. Abnormal placentation: twenty-year analysis. Am J Obstet Gynecol. 2005;192:1458-61. 
31. Bencaiova G, Burkhardt T, Beinder E. Abnormal placental invasion experience at 1 center. J Reprod Med. 2007;52:709-14.

32. Bretelle $F$, Courbière $B$, Mazouni $C$, Agostini A, Cravello L, Boubli L, et al. Management of placenta accreta: morbidity and outcome. Eur J Obstet Gynecol Reprod Biol. 2007;133:34-9.

33. Umezurike CC, Nkwocha G. Placenta accreta in Aba, south eastern, Nigeria. Niger J Med. 2007;16:219-22.

34. Eller AG, Porter TF, Soisson P, Silver RM. Optimal management strategies for placenta accreta. BJOG. 2009;116:648-54.

35. Esh-Broder E, Ariel I, Abas-Bashir N, Bdolah Y, Celnikier DH. Placenta accreta is associated with IVF pregnancies: a retrospective chart review. BJOG. 2011;118:1084-9.

36. Woodring TC, Klauser CK, Bofill JA, Martin RW, Morrison JC. Prediction of placenta accreta by ultrasonography and color Doppler imaging. J Matern Fetal Neonatal Med. 2011;24:118-21.

37. Lim PS, Greenberg M, Edelson MI, Bell KA, Edmonds PR, Mackey AM. Utility of ultrasound and MRI in prenatal diagnosis of placenta accreta: a pilot study. AJR Am J Roentgenol. 2011;197:1506-13.

38. Grace Tan SE, Jobling TW, Wallace EM, McNeilage LJ, Manolitsas T, Hodges RJ. Surgical management of placenta accreta: a 10-year experience. Acta Obstet Gynecol Scand. 2013;92:445-50. 
39. Guleria K, Gupta B, Agarwal S, Suneja A, Vaid N, Jain S. Abnormally invasive placenta: changing trends in diagnosis and management. Acta Obstet Gynecol Scand. 2013;92:461-4.

40. Higgins MF, Monteith C, Foley M, O'Herlihy C. Real increasing incidence of hysterectomy for placenta accreta following previous caesarean section. Eur $\mathrm{J}$ Obstet Gynecol Reprod Biol. 2013;171:54-6.

41. Upson K, Silver RM, Greene R, Lutomski J, Holt VL. Placenta accreta and maternal morbidity in the Republic of Ireland, 2005-2010. J Matern Fetal Neonatal Med. 2014;27:24-9.

42. Brennan DJ, Schulze B, Chetty N, Crandon A, Petersen SG, Gardener G, et al. Surgical management of abnormally invasive placenta: a retrospective cohort study demonstrating the benefits of a standardized operative approach. Acta Obstet Gynecol Scand. 2015;94:1380-6.

43. Mehrabadi A, Hutcheon JA, Liu S, Bartholomew S, Kramer MS, Liston RM, et al; Maternal Health Study Group of Canadian Perinatal Surveillance System (Public Health Agency of Canada). Contribution of placenta accreta to the incidence of postpartum hemorrhage and severe postpartum hemorrhage. Obstet Gynecol. $2015 ; 125: 814-21$.

44. Vinograd A, Wainstock T, Mazor M, Beer-Weisel R, Klaitman V, Dukler D, et al. Placenta accreta is an independent risk factor for late pre-term birth and perinatal mortality. J Matern Fetal Neonatal Med. 2015;28:1381-7.

45. Michikawa T, Morokuma S, Yamazaki S, Fukushima K, Kato K, Nitta H. Exposure to air pollutants during the early weeks of pregnancy, 
and placenta praevia and placenta accreta in the western part of Japan. Environ Int. 2016;92-93:464-70.

46. Baldwin HJ, Patterson JA, Nippita TA, Torvaldsen S, Ibiebele I, Simpson JM, et al. Maternal and neonatal outcomes following abnormally invasive placenta: a population-based record linkage study. Acta Obstet Gynecol Scand. 2017;96:1373-81.

47. Weiniger CF, Einav S, Deutsch L, Ginosar Y, Ezra Y, Eid L. Outcomes of prospectively-collected consecutive cases of antenatal-suspected placenta accreta. Int J Obstet Anesth. 2013;22:273-9.

48. Bowman ZS, Eller AG, Bardsley TR, Greene T, Varner MW, Silver RM. Risk factors for placenta accreta: A large prospective cohort. Am J Perinatol. 2014;31:799-804.

49. Fitzpatrick K, Sellers S, Spark P, Kurinczuk J, Brocklehurst P, Knight M. The management and outcomes of placenta accreta, increta, and percreta in the UK: a population-based descriptive study. BJOG. 2014;121:62-71.

50. Bailit JL, Grobman WA, Rice MM, et al; Eunice Kennedy Shriver National Institute of Child Health and Human Development (NICHD) Maternal-Fetal Medicine Units (MFMU) Network. Morbidly adherent placenta treatments and outcomes. Obstet Gynecol. 2015;125:683-9.

51. Kelekci S, Ekmekci E, Aydogmus S, Gencdal S. A comprehensive surgical procedure in conservative management of placenta accreta: a case series. Medicine (Baltimore). 2015;94:e529. 
52. Farquhar CM, Li Z, Lensen S, McLintock C, Pollock W, Peek MJ et al. Incidence, risk factors and perinatal outcomes for placenta accreta in Australia and New Zealand: a case-control study. BMJ Open. 2017;7:e017713.

53. Irving C, Hertig AT. A study of placenta accreta. Surgery, Gynecol Obstet 1937;64:178-200.

54. Luke RK, Sharpe JW, Greene RR. Placenta accreta: The adherent or invasive placenta. Am J Obstet Gynecol 1966;95:660-8.

55. Balayla J, Bondarenko HD. Placenta accreta and the risk of adverse maternal and neonatal outcomes. J Perinat Med. 2013;41:141-9.

56. Esakoff TF, Handler SJ, Granados JM, Caughey AB. PAMUS: placenta accreta management across the United States. J Matern Fetal Neonatal Med. 2012;25:761-5.

57. Wright JD, Silver RM, Bonanno C, Gaddipati S, Lu YS, Simpson LL, et al. Practice patterns and knowledge of obstetricians and gynecologists regarding placenta accreta. J Matern Fetal Neonatal Med. 2013;26:1602-9.

58. Jauniaux E, Bhide A. Prenatal ultrasound diagnosis and outcome of placenta previa accreta after cesarean delivery: a systematic review and meta-analysis. Am J Obstet Gynecol. 2017;217:27-36.

59. Cal M, Ayres-de-Campos D, Jauniaux E. International survey of practices used in the diagnosis and management of placenta accreta spectrum disorders. Int $\mathrm{J}$ Gynaecol Obstet. 2018;140:307-11.

60. Tikkanen M, Paavonen J, Loukovaara M, Stefanovic V. Antenatal diagnosis of placenta accreta leads to reduced blood loss. Acta Obstet Gynecol Scand. 
2011;90:1140-6.

61. Chantraine F, Braun T, Gonser M, Henrich W, Tutschek B. Prenatal diagnosis of abnormally invasive placenta reduces maternal peripartum hemorrhage and morbidity. Acta Obstet Gynecol Scand. 2013;92:439-44.

62. O'Brien JM, Barton JR, Donaldson ES. The management of placenta percreta: conservative and operative strategies. Am J Obstet Gynecol. 1996;175:1632-8.

63. Solheim KN, Esakoff TF, Little SE, Cheng YW, Sparks TN, Caughey AB. The effect of cesarean delivery rates on the future incidence of placenta previa, placenta accreta, and maternal mortality. J Matern Fetal Neonatal Med. 2011;24:1341-6. 


\section{Figure legends}

Fig 1: Flow diagram showing the selection of reports included in the review.

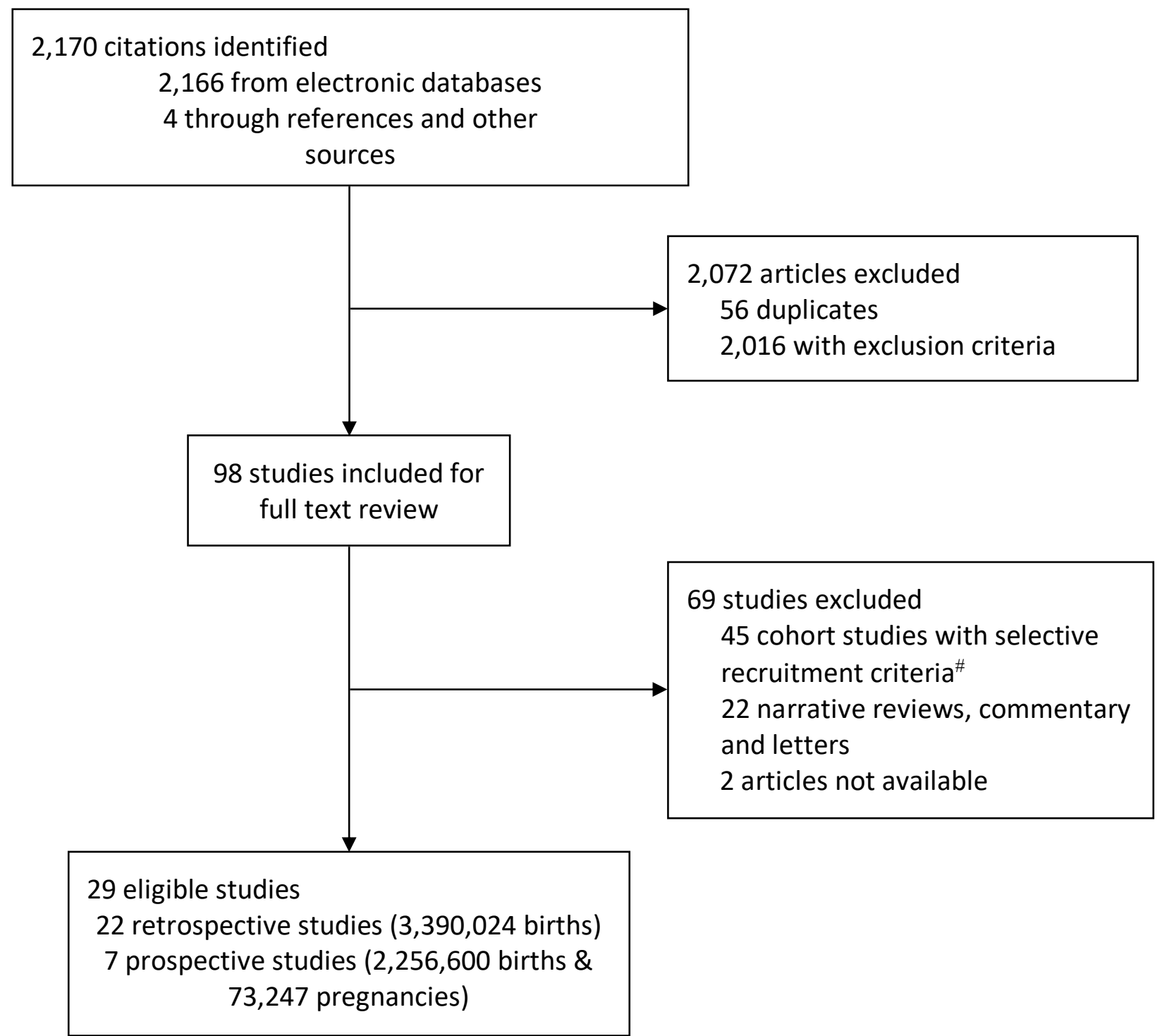

\# Prior caesarean delivery; aneuploidy screening; maternal mortality or environment factor. 
Fig 2: Quality assessment of population studies included in the systematic review on prevalence of PAS using the Quadas-2 tool for the quality assessment of diagnostic accuracy studies.

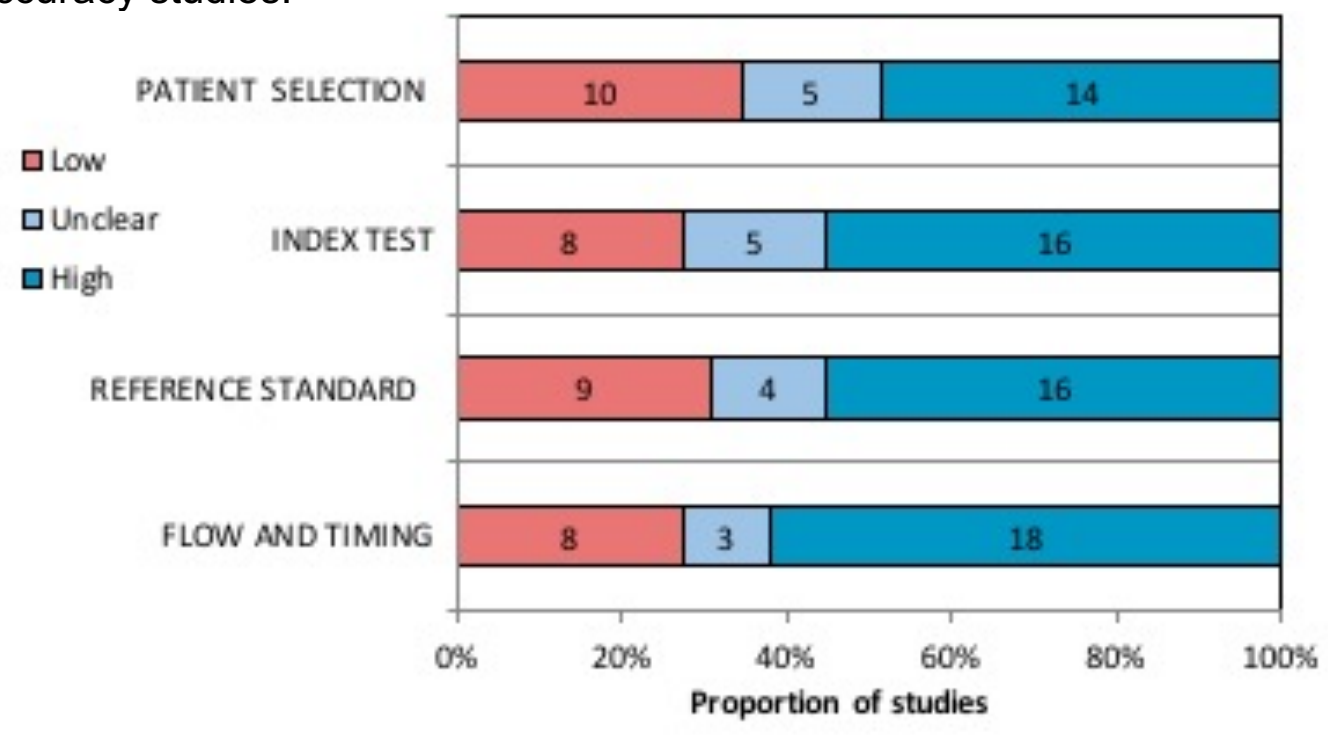

Fig 3: Forest plots of prevalence data heterogeneity in prospective and retrospective population studies.

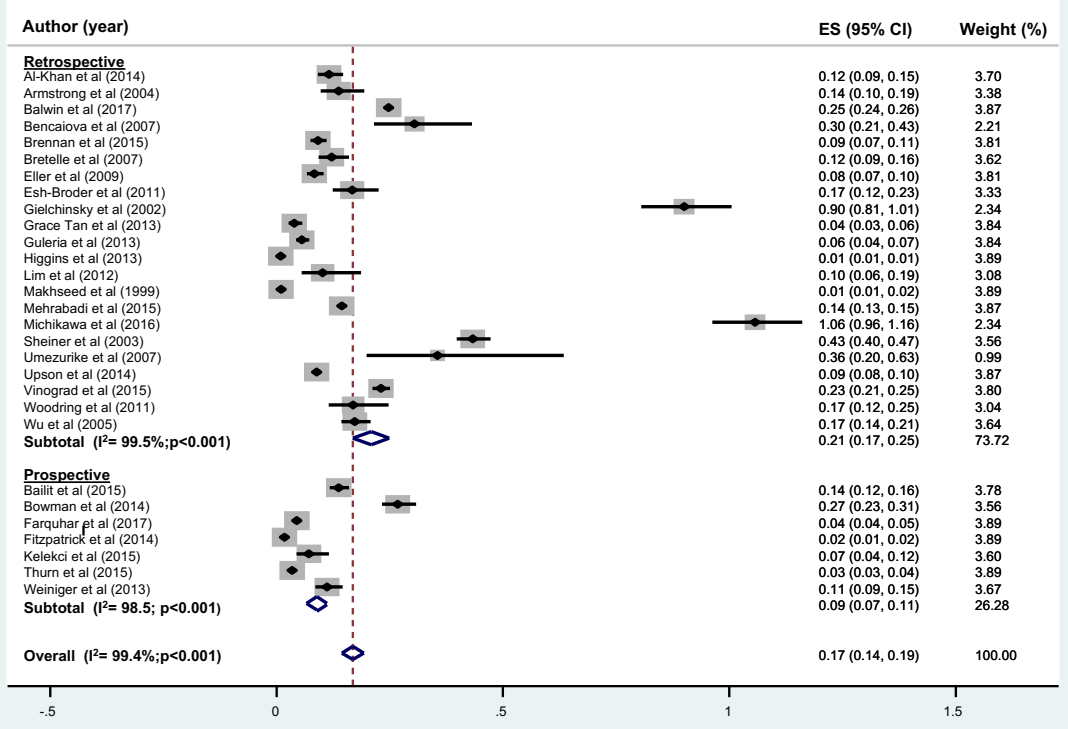

